\title{
ANÁLISE DO RISCO DE INSOLVÊNCIA PELO MODELO DE COX: UMA APLICAÇÃO PRÁTICA
}

RESUMO

A previsão de insolvência é um fator importante para o sistema bancário e, por esse motivo, vem sendo estudada por vários autores. Com o intuito de corroborar esses estudos, este trabalho avaliou a situação financeira das cooperativas de crédito rural do Estado de Minas Gerais entre 1998 e 2001, buscando verificar se as mudanças que afetaram o sistema bancário após o Plano Real também atingiram as cooperativas analisadas. Para avaliar o risco de insolvência, utilizou-se o modelo de risco proporcional de Cox (Cox, 1972). Empregou-se o conceito de insolvência como o de encerramento da cooperativa, patrimônio líquido negativo e/ou 40\% de resultados finais negativos. Como resultado, verificou-se que, nas cooperativas analisadas, os indicadores importantes para avaliar o risco relativo de insolvência foram os índices de "liquidez geral", "encaixe" e "despesa com pessoal". Apenas 1 cooperativa, entre as 107 pesquisadas, encontrava-se na faixa de risco de insolvência determinada pelo modelo.

\section{Valéria Gama Fully Bressan \\ CEPEAD/CAD/UFMG}

\author{
Marcelo José Braga \\ UFV
}

\section{Aureliano Angel Bressan CEPEAD/CAD/UFMG}

\begin{abstract}
Insolvency prediction is an important issue for the banking sector and, for this reason, has been studied by many researchers. Aiming to corroborate these studies, this paper evaluates the financial profile of the agricultural credit cooperatives in the State of Minas Gerais, Brazil, between 1998 and 2001, trying to verify if the changes that affected the banking sector in Brazil after the Real plan in 1994 had also affected the analyzed cooperatives. The proportional hazard model of Cox (Cox, 1972) was applied to evaluate the insolvency risk. The definition of insolvency adopted is associated to the failure of the cooperative, negative equity and/or $40 \%$ of negative final results. The estimates indicate that the most important indicators to evaluate the relative risk of insolvency were the "general liquidity", "short-term liquidity" and "personnel fees". Only 1 cooperative, between the 107 analyzed, was in the insolvency risk range determined by the model.
\end{abstract}

PALAVRAS-CHAVE Insolvência, modelo de risco proporcional de Cox, cooperativas de crédito.

KEY WORDS Insolvency, Cox's proportional hazard model, credit cooperatives. 


\section{INTRODUÇÃo}

Verificaram-se, após a implantação do Plano Real em julho de 1994, falências, intervenções e fusões de diversas instituições no sistema financeiro brasileiro. Essas ocorrências estavam relacionadas com a transição para um ambiente macroeconômico com baixas taxas inflacionárias e com maior exposição ao fluxo internacional de capitais. Os índices de inflação apresentaram queda da ordem de $30 \%$ ao mês para cerca de $1,5 \%$ ao mês. Os ganhos decorrentes do floating foram reduzidos de US $\$ 10$ bilhões para menos de US\$ 500 milhões, o que obrigou os bancos a buscar fontes alternativas de receitas (Matias e Siqueira, 1996). O acirramento da concorrência, com a entrada de bancos estrangeiros no país, fez com que muitos bancos tivessem de passar por algum tipo de ajuste, como transferência de controle acionário, intervenção e/ou liquidação por parte do Banco Central (Janot, 1999). Do total de 271 bancos existentes no início do Plano Real, mais de 50 passaram por algum tipo de intervenção oficial (Rocha, 1999).

Paralelamente, houve um crescimento expressivo do número de cooperativas de crédito no país, com destaque para as cooperativas de crédito rural, que passam a constituir fonte importante de recursos para o agronegócio brasileiro. Berzoini e Souza (2001) destacam a importância das cooperativas de crédito rural para o agronegócio, importância esta que está relacionada ao acesso a linhas de crédito mais acessíveis em termos de encargos financeiros, permitindo o repasse de recursos a encargos menores para os cooperados, se comparado com os custos de financiamento praticados pelo setor bancário.

No sistema financeiro brasileiro, diversos papéis poderiam ser atribuídos a um sistema cooperativo de crédito. Como não têm finalidade lucrativa, essas cooperativas poderiam ajudar a diminuir os spreads bancários, desde que organizadas dentro de uma rede, em associação com um grande banco de economia mista, como o DG Bank, da Alemanha (Berzoini e Souza, 2001). No caso brasileiro, as cooperativas de crédito estão associadas ao Banco Cooperativo do Brasil (Bancoob), constituído em 1997 com o objetivo de proporcionar autonomia operacional às cooperativas de crédito (Crediminas, 1997).

Todavia, a despeito da flexibilidade e das taxas competitivas do sistema de crédito cooperativo, torna-se importante avaliar a situação de insolvência do setor. Isso porque, dadas as restrições da política monetária brasileira após a implementação do Plano Real, com elevação das taxas de juros, estagnação econômica e conseqüente redução do consumo e do investimento produtivo, houve uma elevação no risco de inadimplência do setor bancário em geral (Rocha, 1999).

Nessa perspectiva, diversos estudos analisaram o risco de insolvência nos bancos comerciais, com destaque para os trabalhos de Janot (1999) e Rocha (1999), os quais aplicaram modelos estatísticos de previsão de insolvência com base em indicadores econômico-financeiros de bancos comerciais brasileiros. Entretanto, não existe na literatura acadêmica nacional nenhum estudo tratando da previsão de insolvência para as cooperativas de crédito rural que, dado o crescimento observado na última década, assumem importância crescente no financiamento do agronegócio brasileiro (Schröder, 1999).

Assim, no contexto de redução do crédito rural oficial, com mudanças no cenário econômico durante a década de 1990, a consolidação das cooperativas de crédito como alternativa para suprir as demandas de financiamento do agronegócio e a inexistência de estudos que focalizem o risco de insolvência nas cooperativas de crédito rural brasileiras, o presente estudo busca avaliar o risco de insolvência no segmento no Estado de Minas Gerais, pois, de 369 cooperativas de crédito rural existentes no Brasil, 112, ou 30,4\%, encontram-se em Minas (OCB, 2001). Em 2001, essas cooperativas possuíam 176.590 associados e empregavam 2.220 pessoas, segundo dados da Organização das Cooperativas do Estado de Minas Gerais (OCEMG, 2001).

No conjunto, as cooperativas de crédito rural mineiras têm, em média, 11 anos de funcionamento, com um faturamento em 1998 de $\mathrm{R} \$ 112.320 .000,00$, o que corresponde a uma média de $\mathrm{R} \$ 702.025,51$ por cooperativa (Sescoop, 2000). De 1997 para 1998, o capital social dessas instituições aumentou $52,3 \%$, passando de $\mathrm{R} \$ 62.394 .570,00$ para $\mathrm{R} \$ 95.045 .188,00$, com um capital social médio por cooperativa de $\mathrm{R} \$$ 477.614,01 (Sescoop, 2000).

Ressalte-se, portanto, a representatividade das cooperativas de crédito para o Estado de Minas Gerais, especialmente para o setor rural, pois essas empresas representam uma alternativa para a maior democratização do crédito no setor, que é fornecido de forma mais adequada à realidade dos agricultores familiares (Schröder, 1999). No entanto, para que as cooperativas possam realmente atender às necessidades financeiras dos produtores rurais mineiros, é importante que 
tenham estrutura financeira sólida, com baixos riscos de insolvência.

A importância da análise do risco de insolvência está essencialmente relacionada com a sobrevivência da instituição financeira que concede o crédito. Outro fator importante é a possibilidade de, por meio de medidas de risco adequadas, gerar previsões acerca da probabilidade de insolvência. Desse modo, medidas do risco de insolvência podem ser utilizadas como instrumentos importantes para o gerenciamento do crédito e das decisões de investimento e financiamento de instituições financeiras.

Este trabalho pretende contribuir ainda com a ampliação do conjunto de informações a respeito do cooperativismo de crédito mineiro, pois a maior parte dos trabalhos desenvolvidos envolvendo fatores financeiros de cooperativas contempla informações a respeito de cooperativas no Paraná (Menegário e Araújo, 2001; Rodrigues, 2000; Schröder, 1999; Gimenes, 1998), Rio Grande do Sul (Masy, 1996; Benetti, 1985) e São Paulo (Panzutti, 1997).

Nesse contexto, o objetivo específico do presente estudo consiste em avaliar o risco de insolvência das cooperativas de crédito rural integrantes do sistema Crediminas, utilizando, como ferramenta de análise, o modelo de risco proporcional de Cox. A aplicabilidade dos resultados da pesquisa está relacionada com a verificação da importância de indicadores financeiros específicos para a previsão de insolvência e a conseqüente utilização destes como ferramenta auxiliar para o monitoramento realizado pela Cooperativa Central de Crédito Rural de Minas Gerais Ltda. Crediminas -, além de servir como instrumento de apoio à decisão para os dirigentes das cooperativas singulares, que poderão implementar medidas corretivas para ajustar a situação financeira destas.

\section{DEFINIÇÃO OPERACIONAL DAS VARIÁVEIS ESTUDADAS}

Com o intuito de definir as variáveis que serão utilizadas no modelo empírico adotado neste trabalho, esta seção apresenta, inicialmente, uma breve discussão acerca das diversas definições do conceito de insolvência e qual definição será adotada no presente estudo. Em seguida, são apresentadas as variáveis econômico-financeiras de análise e previsão do risco de insolvência que serão incorporadas ao modelo com vistas a gerar os resultados necessários para a inferência.

\section{Diversas perspectivas sobre o fenômeno insolvência}

A insolvência tem sido estudada por vários autores que buscam indicações de sua possível ocorrência de modo que as organizações, financeiras ou não, possam se estruturar adequadamente, reduzindo a possibilidade de falência. Destaca-se, na literatura, a inexistência de um consenso em relação à definição do conceito de insolvência e tampouco há uma metodologia adequada para a construção de modelos de previsão de insolvência (Gimenes, 1998).

Segundo Gitman (1997), a insolvência ocorre quando a empresa é incapaz de pagar suas obrigações em dia. Para Altman (1968), a insolvência de uma empresa é declarada quando os acionistas recebem uma rentabilidade por suas ações menor que a oferecida pelo mercado, que trabalha com ações similares. Gimenes (1998) considerou estado de insolvência quando a empresa declara suspensão de pagamentos ou quebra, isto é, quando não pode honrar suas dívidas. Para Silva (1983), as empresas insolventes são aquelas que tiveram processos de concordata, requerida e/ou deferida, e/ou falência decretada. Já Matias e Siqueira (1996) utilizaram o conceito de insolvência como o fato de a instituição sofrer liquidação ou intervenção do Banco Central. Nesse aspecto, Tzirulnik (1997) ressalta que a intervenção só poderá ser realizada se forem verificadas anormalidades nos negócios sociais da instituição financeira. A lei prevê as seguintes anormalidades: má administração, infrações a dispositivos bancários e impontualidade ou presunção de insolvência.

Segundo Janot (1999), uma instituição financeira torna-se insolvente quando seu patrimônio líquido se encontra negativo ou se for impossível continuar suas operações sem incorrer em perdas que resultariam em patrimônio líquido negativo. Esse autor destacou ainda que outra forma de definir insolvência ocorre quando essa instituição é colocada em evidência pelo supervisor responsável. No entanto, esse tipo de abordagem apresenta desvantagem por depender de critérios subjetivos de julgamento. "Por outro lado, como a colocação de um banco em evidência precede sua liquidação, um modelo que preveja esta classificação provê um tempo maior para ações corretivas" (Janot, 1999, p. 3).

$\mathrm{Na}$ literatura sobre o assunto, os fatores que contribuem para um estado de insolvência são tratados sob perspectivas distintas. Para Munoz (2001), são as condições econômicas e as medidas políticas que exercem influência sobre uma situação de solvência ou insol- 
vência. Com relação aos bancos, destacou-se que a insolvência é devida a fatores como fraudes, imprudência administrativa e ocorrência de prejuízos consecutivos, além da influência dos aspectos macroeconômicos. Gimenes (1998) apontou causas de origem externa, como forte queda de demanda, fase depressiva da economia, crises econômicas, políticas governamentais e mudanças sociais radicais e significantes. Esse mesmo autor citou ainda causas internas, como ineficácia da direção e estratégias errôneas e inadequadas, além de sistema produtivo ineficiente, endividamento excessivo e alta morosidade, entre outros. Backer e Gosman (1978) consideraram como parâmetros para insolvência a análise de debêntures, o crédito comercial e os empréstimos bancários, pois essas são formas de financiamento por capital de terceiros e, a princípio, quanto maior a dependência desse tipo de financiamento, maior a probabilidade de ocorrer insolvência.

Alguns autores, ao avaliar a situação de insolvência e de falência por meio de indicadores financeiros, constataram, conforme se pode verificar no Quadro 1, os seguintes indicadores como significativos:

Almeida (1993), ao discutir a evolução dos riscos de falência em empresas, definiu que a metodologia para avaliar esses riscos se divide em quatro pontos: 1) construção de uma amostra que contenha empresas solventes e insolventes; 2) importância de selecionar variáveis que indicarão o fenômeno em questão, com base nas demonstrações financeiras das empresas; 3) seleção de um modelo, ou técnica estatística, que permita modelar as variáveis extraídas das demonstrações financeiras - citando como exemplos a análise discriminante e a análise logística; e 4) validação do modelo, para verificação de sua capacidade discriminante.

Esse autor destacou que outro elemento importante para constituição da amostra é a definição do critério para determinar a falência. Relatou que alguns pesquisadores consideraram como falidas as empresas ilíquidas; outros, o fato de as empresas cessarem seus pagamentos; outros, ainda, a suspensão de depósitos de dividendos prioritários, além do fato de as empresas não registrarem suas perdas. Ressalta-se, nesse sentido, a questão da ausência de uma teoria que explique, de maneira rigorosa, os processos de falência, dando margem a diversas interpretações sobre os possíveis determinantes desse fenômeno.

Constata-se, assim, que não existe consenso em relação a quais indicadores são mais relevantes para de- terminar a insolvência ou não de um banco ou empresa, bem como para indicar situação de falência. Gimenes (1998) destacou a questão da ausência de uma teoria econômica que subsidie a escolha de variáveis para previsão de insolvência. No entanto, esse fator não impede que sejam elaborados indicadores objetivos de análise para avaliar e prever a situação de insolvência ou falências.

No que tange à previsão de insolvência, Kanitz (1978) destacou vários estudos mostrando que as empresas insolventes começam a dar sinais de dificuldades bem antes de chegar ao ponto crítico de uma falência ou concordata e que talvez seja impossível prever uma falência com $100 \%$ de certeza, mas é perfeitamente possível identificar aquelas empresas que têm mais possibilidades de falir em um futuro não muito distante.

No presente estudo, o conceito de insolvência utilizado baseia-se na definição de Janot (1999) adaptada às características do sistema cooperativo de crédito. Assim, cooperativas classificadas como insolventes foram aquelas que fecharam ou tiveram patrimônio líquido ajustado negativo ou ainda o mínimo de 40\% de resultados finais negativos no período de agosto de 1998 a agosto de 2001, e as que não apresentavam essas características foram classificadas como solventes.

\section{Definição das variáveis de controle}

Para operacionalizar o modelo de risco proporcional de Cox de modo a gerar previsões do risco de insolvência das cooperativas de crédito rural de Minas Gerais, utilizaram-se indicadores financeiros extraídos dos balanços contábeis dessas cooperativas e identificou-se o tempo de sobrevivência de cada cooperativa, em meses, considerando o início da análise (retroativa) o mês de agosto de 2001. Para as cooperativas classificadas como insolventes, informou-se ao modelo de Cox a ocorrência de falha ${ }^{1}$. Já nas 92 cooperativas em que não se detectou insolvência, informou-se ao modelo a ocorrência de censura ${ }^{2}$, ou seja, no período de 37 meses de análise, a ocorrência de um maior número de cooperativas solventes.

Os indicadores financeiros que constituíram as variáveis explicativas para operacionalização do risco proporcional de Cox foram retirados, em parte, do Manual. Não foram utilizados todos os indicadores por existir diferença entre as contas dos balanços das cooperativas de crédito rural e as mencionadas no Manual de Análise Austin Asis. Desse modo, adequaram-se os indicadores em conformidade com as contas contábeis disponíveis. A sugestão de utilizar esse manual foi extraí- 
da dos trabalhos de Matias e Siqueira (1996) e Rocha (1999). Foram utilizados os seguintes indicadores econômico-financeiros descritos no Quadro 2.

\section{MODELO EMPÍRICO}

\section{Modelo de risco proporcional de Cox}

O modelo de Cox permite a análise de dados provenien- tes de tempo de vida, em que a resposta é o tempo até a ocorrência de um evento de interesse, ajustado por co-variáveis (Colosimo, 2001). No presente estudo, o tempo de vida corresponde desde o tempo em que as cooperativas estão no mercado até a ocorrência do evento, que constitui o fato de as cooperativas se tornarem insolventes, e será ajustado por co-variáveis formadas por indicadores econômico-financeiros.

Quadro 1 - Diferentes abordagens quanto à questão da insolvência e falência.

\begin{tabular}{|c|c|c|}
\hline AUTORES & EVENTO ESTUDADO & INDICADORES FINANCEIROS SIGNIFICATIVOS \\
\hline $\begin{array}{l}\text { Patrick (1936), } \\
\text { apud Silva (1983) }\end{array}$ & Falência & $\begin{array}{l}\text { I. Patrimônio líquido/Passivo } \\
\text { II. Lucro líquido/Patrimônio líquido }\end{array}$ \\
\hline $\begin{array}{l}\text { Winakor e Smith (s.d.), } \\
\text { apud Silva (1983) }\end{array}$ & Falência & I. Capital de giro/Ativo total \\
\hline $\begin{array}{l}\text { Tamari (s.d.), } \\
\text { apud Silva (1988) }\end{array}$ & Falência & $\begin{array}{l}\text { I. Lucro } \\
\text { II. Capital social + Reservas/Passivo total }\end{array}$ \\
\hline $\begin{array}{l}\text { Beaver (1968), apud } \\
\text { Silva (1988) }\end{array}$ & Falência & $\begin{array}{l}\text { I. Geração de caixa/Dívida total } \\
\text { II. Lucro líquido/Ativo total } \\
\text { III. Exigível total/Ativo total } \\
\text { IV. Capital de giro/Ativo total } \\
\text { V. Liquidez corrente } \\
\text { VI. Capital circulante líquido - Estoques/desembolsos operacionais previstos }\end{array}$ \\
\hline Altman (1968) & Falência & $\begin{array}{l}\text { I. Ativo corrente - Passivo corrente/Ativo total } \\
\text { II. Lucros retidos/Ativo total } \\
\text { III. Lucros antes de juros e impostos/Ativo total } \\
\text { IV. Valor de mercado do equity/Exigível total } \\
\text { V. Vendas/Ativo total }\end{array}$ \\
\hline $\begin{array}{l}\text { Matias (1978), } \\
\text { apud Silva (1983) }\end{array}$ & Insolvência & $\begin{array}{l}\text { I. Patrimônio líquido/Ativo total } \\
\text { II. Financiamento e empréstimos bancários/Ativo circulante } \\
\text { III. Fornecedores/Ativo total } \\
\text { IV. Ativo circulante/Passivo circulante } \\
\text { V. Lucro operacional/Lucro bruto } \\
\text { VI. Disponível/Ativo total }\end{array}$ \\
\hline Kanitz (1978) & Insolvência & $\begin{array}{l}\text { I. Lucro líquido/Patrimônio líquido } \\
\text { II. Ativo circulante + Realizável no longo prazo/Exigível total } \\
\text { III. Ativo circulante - Estoque/Passivo circulante e Ativo circulante/Passivo } \\
\text { circulante } \\
\text { IV. Exigível total/Patrimônio líquido }\end{array}$ \\
\hline $\begin{array}{l}\text { Matias e Siqueira } \\
(1996)\end{array}$ & Insolvência & $\begin{array}{l}\text { I. Custo administrativo } \\
\text { II. Comprometimento do patrimônio líquido com crédito em liquidação } \\
\text { III. Evolução da captação de recursos }\end{array}$ \\
\hline Rocha (1999) & Insolvência & I. Margem líquida \\
\hline Martins (2003) & $\begin{array}{l}\text { Insolvência } \\
\text { (concordata) }\end{array}$ & $\begin{array}{l}\text { I. Empréstimos bancários/Ativo circulante } \\
\text { II. Retorno sobre o patrimônio líquido }\end{array}$ \\
\hline
\end{tabular}


O modelo de risco proporcional de Cox (Cox, 1972) pode ser descrito da seguinte forma: sendo t o tempo até a insolvência de determinada cooperativa de crédito rural, pode-se, então, definir a função de sobrevivência dada por $S(t)$ como a probabilidade de uma cooperativa sobreviver mais do que t períodos:

$$
S(t)=\operatorname{Pr}[T \succ t]=1-F(t)
$$

em que $\mathrm{F}(\mathrm{t})$ é a função de distribuição cumulativa do tempo de insolvência e a função-densidade de probabilidade é igual a $f(t)=-S^{\prime}(t)$. Embora a distribuição do tempo de insolvência possa ser descrita por $F(t)$ ou $\mathrm{f}(\mathrm{t})$, ela é, geralmente, caracterizada pela função de risco:

$$
h(t)=\lim _{d t \rightarrow 0} \frac{P[t \prec T \prec t+d t / T \succ t]}{d t}=\frac{-S^{\prime}(t)}{S(t)}
$$

A função de risco, $\mathrm{h}(\mathrm{t})$, dá a probabilidade de insolvência no próximo instante, dado que a cooperativa sobreviveu até o período t. Existe uma série de vantagens estatísticas em estimar $\mathrm{h}(\mathrm{t})$ em vez de $\mathrm{F}(\mathrm{t})$, ou $\mathrm{f}(\mathrm{t})$, de acordo com Cox e Oakes (1984), apud Rocha (1999). Uma vez obtidas as estimativas de $\mathrm{h}(\mathrm{t})$, as de $\mathrm{F}(\mathrm{t})$ e $\mathrm{f}(\mathrm{t})$ são imediatamente obtidas usando-se:

Quadro 2 - Indicadores econômico-financeiros utilizados no estudo.

\section{GRUPO 1 - INDICADORES DE ESTRUTURA}

I. Capitalização = Patrimônio líquido/Passivo real

II. Imobilização = Ativo permanente/Patrimônio líquido

III. Capital de giro = Patrimônio líquido - Ativo permanente/ Patrimônio líquido

IV. Alavancagem = Captação total/Patrimônio líquido

\section{GRUPO 3 - INDICADORES DE CUSTO E DESPESAS}

I. Despesa com pessoal $=$ Despesa com pessoal/Captação total

II. Despesa administrativa = Despesa administrativa/Captação total

III. Despesa total = Total das despesas/Captação total

\section{GRUPO 5 - INDICADORES DE CRESCIMENTO}

I. Crescimento da aplicação total = Aplicação total do último período/Aplicação total do período anterior

II. Crescimento da captação total = Captação total do último período/Captação total do período anterior

III. Crescimento da receita operacional $=$ Receita operacional do último período/Receita operacional do período anterior

$$
F(t)=1-\exp \left[-\int_{0}^{1} h(u) d u\right]
$$

$$
f(t)=F^{\prime}(t)
$$

em que a integral entre colchetes é denominada função de risco integrada: não tem uma interpretação imediata, mas constitui um instrumento básico do teste de especificação do modelo.

Dependendo das hipóteses sobre a natureza da distribuição do tempo de insolvência, diferentes tipos de modelos de risco proporcional podem ser especificados. Suponha-se que $h(t / X, \beta)$ seja a função de risco no tempo t para uma cooperativa qualquer, onde $\mathrm{X}$ representa um conjunto de variáveis que afetam a probabilidade de insolvência e $\beta$, os coeficientes que descrevem como cada variável característica afeta a probabilidade de insolvência a serem estimados. Em um modelo de risco proporcional, $\mathrm{h}(\mathrm{t} / \mathrm{X}, \beta)=\mathrm{h}_{\mathrm{o}}(\mathrm{t}) \Psi(\mathrm{X}, \beta)$, em que $\Psi(X, \beta)$ é alguma função de $X$, tal que $\Psi(0)=$ 1 e h $(\mathrm{t})$ é uma função de risco para uma cooperativa com $\mathrm{X}=0$, denominada baseline hazard function. Se as variáveis explicativas forem centralizadas, de forma que uma cooperativa com $X=0$ tenha valores iguais às médias populacionais, então $h_{0}(t)$ poderá ser pen-
I. Encaixe $=$ Disponibilidades $/$ Depósitos à vista

II. Cobertura voluntária $=$ Disponibilidades/Passivo real

III. Liquidez geral = Ativo circulante e realizável no longo prazo/ Passivo circulante e exigivel no longo prazo

IV. Volume de crédito concedido em relação ao $\mathrm{PL}=$ 0perações de crédito/Patrimônio líquido

\section{GRUPO 4 - INDICADOR DE RENTABILIDADE}

I. Geração de renda $=$ Receitas operacionais/Ativo real Ativo permanente

\section{INDICADORES UTILIZADOS NOS CÁLCULOS}

I. Ativo real $=$ Ativo total - Relações interfinanceiras - Relações interdependentes

II. Passivo real = Passivo total - Relações interfinanceiras Relações interdependentes

III. Aplicação total = Ativo real - Ativo permanente - Diversos

IV. Captação total = Passivo real - Patrimônio líquido - Diversos 
sado como a função de risco de uma cooperativa "média" na população estudada. Nesse caso, em um modelo de risco proporcional, o efeito das variáveis explicativas é multiplicar a função de risco de uma cooperativa média, $h_{o}(t)$, por alguma função $\Psi(X, \beta)$ dos desvios das variáveis explicativas de seus valores médios.

Um caso do modelo de risco proporcional que será utilizado consiste em:

$$
\Psi(X, \beta)=\exp \left(X^{\prime}, \beta\right)
$$

A função de risco é, então, dada por:

$$
h(t / X, \beta)=h_{o}(t) \exp \left(X^{\prime}, \beta\right)
$$

O modelo de Cox, em geral, é denominado semiparamétrico, sendo $h_{o}(t)$ sua parte não-paramétrica e $\exp \left(X^{\prime}, \beta\right)$, sua parte paramétrica. Admite-se que a função de risco baseline $\mathrm{h}_{\mathrm{o}}(\mathrm{t})$ é arbitrária e depende somente do tempo. Além disso, não são requeridas hipóteses distributivas para estimar $\beta$ ou $h_{o}(t)$. A segunda parte de (6), no entanto, depende do vetor dos parâmetros de regressão $\beta$. A função-sobrevivência correspondente ao modelo de risco proporcional de Cox, que é usada para calcular a probabilidade de uma cooperativa sobreviver mais do que determinado período de tempo, é dada pela seguinte equação:

$$
S(t / X, \beta)=S_{0}(t)^{\exp \left(X^{\prime} \beta\right)}
$$

onde

$$
S(t)=\exp \left[-\int_{0}^{1} h_{0}(u) d u\right]
$$

é a função-sobrevivência correspondente à função de risco baseline $\mathrm{h}_{\mathrm{o}}(\mathrm{t})$. Tal como na função de risco, $\mathrm{S}_{\mathrm{o}}(\mathrm{t})$ é denominada função-sobrevivência baseline e depende somente do tempo. Ela é a mesma para todas as cooperativas. A integral entre parênteses, por correspondência, é denominada função de risco integrada baseline.

Para ajustar o modelo, é necessária uma amostra que contenha cooperativas insolventes e uma amostra com cooperativas solventes. Deve-se escolher para ambas as amostras o horizonte de tempo relevante antes da insolvência, a fim de que a probabilidade baseline relevante seja determinada. De posse dos co- eficientes estimados, substituem-se os valores das variáveis características relevantes na fórmula anterior, obtendo-se a função-sobrevivência.

Para operacionalização do modelo de risco proporcional de Cox, as variáveis explicativas foram dicotomizadas. As variáveis assumiram os seguintes pontos de corte: capitalização $(0,02)$, imobilização $(-1)$, capital de giro (1), alavancagem $(0,5)$, encaixe (1), cobertura voluntária $(0,2)$, liquidez geral (1), volume de crédito em relação ao PL $(0,1)$, despesa total $(-0,03)$, despesa com pessoal $(-0,005)$, despesa administrativa $(-0,009)$, crescimento da aplicação total $(0,9)$, crescimento da captação total $(0,8)$, crescimento da receita operacional $(1,5)$ e geração de renda $(0,06)$. Valores superiores ou iguais aos pontos de corte assumiram valor zero e valores menores que o ponto, valor 1 . As estimativas foram feitas utilizando o software SPSS 10.0.

É importante destacar que também foi necessário determinar o mês da ocorrência da falha para operacionalização do modelo. Nas cooperativas que fecharam, foi utilizado o mês do fechamento com base nos dados disponibilizados pela Crediminas. No caso do patrimônio líquido ajustado (PLA) negativo e do resultado final ${ }^{3}$ (RF) negativo, foi determinado que o último mês com ocorrência de PLA negativo e/ou RF negativo seriam o mês da ocorrência da falha.

\section{POPULAÇÃO, AMOSTRA E COLETA DE DADOS}

Os indicadores econômico-financeiros utilizados neste estudo foram calculados a partir dos balancetes mensais das 107 cooperativas singulares filiadas à Crediminas, no período de agosto de 1998 a agosto de 2001. Com base nos dados da OCB (2001), existiam 112 cooperativas de crédito rural no Estado de Minas Gerais em 1998, de forma que a amostra contemplou $96 \%$ da população, ou seja, pode-se afirmar que os dados refletiram a situação financeira das cooperativas de crédito rural mineiras. Dessas cooperativas, 15 foram classificadas como insolventes e 92 como solventes, conforme o critério de insolvência definido anteriormente.

Os dados referentes aos balanços contábeis utilizados no estudo são de natureza secundária e foram obtidos junto à Crediminas. A classificação das cooperativas em solventes/insolventes e os indicadores econômico-financeiros foram calculados posteriormente pelos autores com base nesses balanços. 


\section{ANÁLISE E DISCUSSÃO DOS RESULTADOS}

A análise de risco relativo de insolvência permitiu verificar, em função dos indicadores financeiros das cooperativas, qual a possibilidade de ocorrer insolvência, dado que cada cooperativa sobreviveu até o registro dessa situação. Esse risco foi calculado com base nos dados de sobrevivência, ou seja, as cooperativas que foram classificadas como solventes foram censuradas com o período de 37 meses. Já nas insolventes, registrou-se o tempo de falha, cujos meses de registros de insolvências se encontram na Tabela 1.

Primeiro, verificou-se a suposição do modelo, isto é, a existência de riscos proporcionais para cada uma das co-variáveis, constatando-se que todas as variáveis significativas para o modelo de Cox atenderam a essa exigência. Segundo Colosimo (2001), no modelo de
Cox o que é avaliado é o exponencial do coeficiente $\beta$, que na Tabela 2 está representado pelo risco relativo (RR). Isso porque, segundo esse autor, não há interpretação direta para os coeficientes $\beta$ s, uma vez que a análise destes deve estar conjugada com os demais valores da função de risco da equação (6).

As variáveis explicativas significativas a $5 \%$ de probabilidade para operacionalizar o modelo de risco proporcional de Cox foram crescimento da captação total, liquidez geral, encaixe, despesa com pessoal, crescimento da receita operacional e alavancagem (Tabela 2).

A captação total apresentou ponto de corte de 0,8 , ou seja, esse valor indica um decréscimo da captação total de um mês para o outro. Assim, verifica-se que as cooperativas que tiverem esse indicador menor que 0,8 têm mais possibilidades de se tornarem insolventes, isto é, o risco das cooperativas de crédito rural

Tabela 1 - Datas das ocorrências do evento insolvência (1998 a 2001).

\begin{tabular}{|c|c|c|c|}
\hline REGISTRO DE INSOLVÊNCIA & № DE COOPERATIVAS & PERCENTUAL & PERCENTUAL POR ANO \\
\hline Setembro, 1998 & 1 & 6,67 & $1998=6,67$ \\
\hline Março,1999 & 1 & 6,67 & \multirow{2}{*}{$1999=13,33$} \\
\hline Julho, 1999 & 1 & 6,67 & \\
\hline Junho, 2000 & 1 & 6,67 & $2000=6,67$ \\
\hline Janeiro, 2001 & 1 & 6,67 & \multirow{7}{*}{$2001=73,33$} \\
\hline Fevereiro, 2001 & 1 & 6,67 & \\
\hline Abril, 2001 & 1 & 6,67 & \\
\hline Maio, 2001 & 1 & 6,67 & \\
\hline Junho, 2001 & 1 & 6,67 & \\
\hline Julho, 2001 & 2 & 13,33 & \\
\hline Agosto, 2001 & 4 & 26,67 & \\
\hline TOTAL & 15 & 100,00 & 100,00 \\
\hline
\end{tabular}

Tabela 2 - Resultados do ajuste do modelo de regressão de Cox (1998 a 2001).

\begin{tabular}{|l|c|c|c|c|c|}
\hline \multicolumn{1}{|c|}{ CO-VARIÁVEL } & ESTIMATIVA (B) & $\begin{array}{c}\text { DESVIO- } \\
\text { PADRÃ0 }\end{array}$ & $\begin{array}{c}\text { VALOR } \\
\text { DE P }\end{array}$ & $\begin{array}{c}\text { RISCO RELATIVO } \\
\text { (RR) }\end{array}$ & $\begin{array}{c}\text { RR } \\
(\text { IC, 95\%) }\end{array}$ \\
\hline Crescimento captação total & 2,0425 & 0,7444 & 0,0061 & 7,7100 & $(1,79 ; 33,16)$ \\
\hline Liquidez geral & 1,9966 & 0,9571 & 0,0370 & 7,3643 & $(1,12 ; 48,06)$ \\
\hline Encaixe & 2,1214 & 0,8015 & 0,0081 & 8,3432 & $(1,73 ; 40,14)$ \\
\hline Despesa com pessoal & $-1,6586$ & 0,8091 & 0,0404 & 0,1904 & $(0,04 ; 0,93)$ \\
\hline Crescimento receita operacional & $-3,2452$ & 0,8043 & 0,0001 & 0,0390 & $(0,008 ; 0,19)$ \\
\hline Alavancagem & 2,4178 & 1,2349 & 0,0502 & 11,2213 & $(0,1 ; 126,22)$ \\
\hline
\end{tabular}


que possuem captação total menor que 0,8 se tornarem insolventes é de 7,71 vezes o risco daquelas que tiveram captação superior ou igual a 0,8 . Além disso, pode-se afirmar, com $95 \%$ de confiança, que esse risco varia entre 1,79 e 33,16 (Tabela 2). A princípio este resultado é inesperado, indicando que quanto maior a captação total, maior a possibilidade de insolvência.

No entanto, um aumento na captação total significa, no entanto, que a disponibilidade de recursos de terceiros é maior. Portanto, a cooperativa tem maior capacidade de conceder empréstimos aos cooperados. O fator negativo é que, quanto maior a utilização de recursos de terceiros, maior a probabilidade de insolvência.

Analisando o porquê desse resultado contrário ao esperado, constatou-se que, de 107 observações, apenas 5 apresentaram captação total menor que 0,8 e, dessas 5 cooperativas, 2 foram classificadas como solventes e 3 como insolventes, ou seja, a maior parte das cooperativas apresentou captação total maior que 0,8 , e $86 \%$ delas foram classificadas como solventes, de modo que o modelo captou maior risco para valores inferiores ou iguais a 0,8 .

Outro fato que deve ser ressaltado é que as cooperativas necessitam de captação total para poder pagar suas despesas. O que não deve ocorrer é um excesso de captação, porque isso indica uma pressão exercida pela instituição financeira sobre os fornecedores de recursos. O modelo de Cox mostra que um decréscimo constante na captação total aumenta o risco de insolvência nas cooperativas de crédito rural analisadas.
De acordo com as contas que compõem o passivo das cooperativas de crédito rural do Estado de Minas Gerais, em comparação com a fórmula de cálculo descrita na operacionalização das variáveis, constata-se que, basicamente, o indicador de captação é formado pela conta "depósitos" (à vista e a prazo), e uma redução constante nessa conta conduziria a um estado de insolvência.

Já a liquidez geral apresentou risco de insolvência compatível ao esperado, pois, quanto maior a liquidez, menor a chance de a cooperativa tornar-se insolvente, como se pode verificar no Gráfico 1. De acordo com o modelo de Cox, o risco para as cooperativas que possuem liquidez geral menor que 1 é de 7,36 vezes o daquelas que possuem esse indicador maior que 1 . Pode-se afirmar, com $95 \%$ de confiança, que o risco varia de 1,12 a 48,6, ou seja, é uma faixa considerável, informando que, quanto menor a liquidez, maiores as possibilidades de ocorrência de insolvência (Gráfico 1).

Com base nos dados do indicador de liquidez geral para as 107 cooperativas de crédito rural do Estado de Minas Gerais, em agosto de 2001 apenas 1 cooperativa possuía esse indicador menor que 1. Essa é uma primeira indicação da possibilidade de insolvência de uma cooperativa entre as 107 analisadas.

Entretanto, é importante ressaltar que, altos índices de liquidez não necessariamente informam situação financeira saudável, porque ela depende dos critérios adotados pelo setor contábil e de uma análise que relacione os outros indicadores econômico-financeiros das cooperativas. No entanto, baixos índices de liquidez indicam situação de insolvência.

\section{Gráfico 1 - Função de risco relativo de insolvência para a co-variável liquidez geral.}

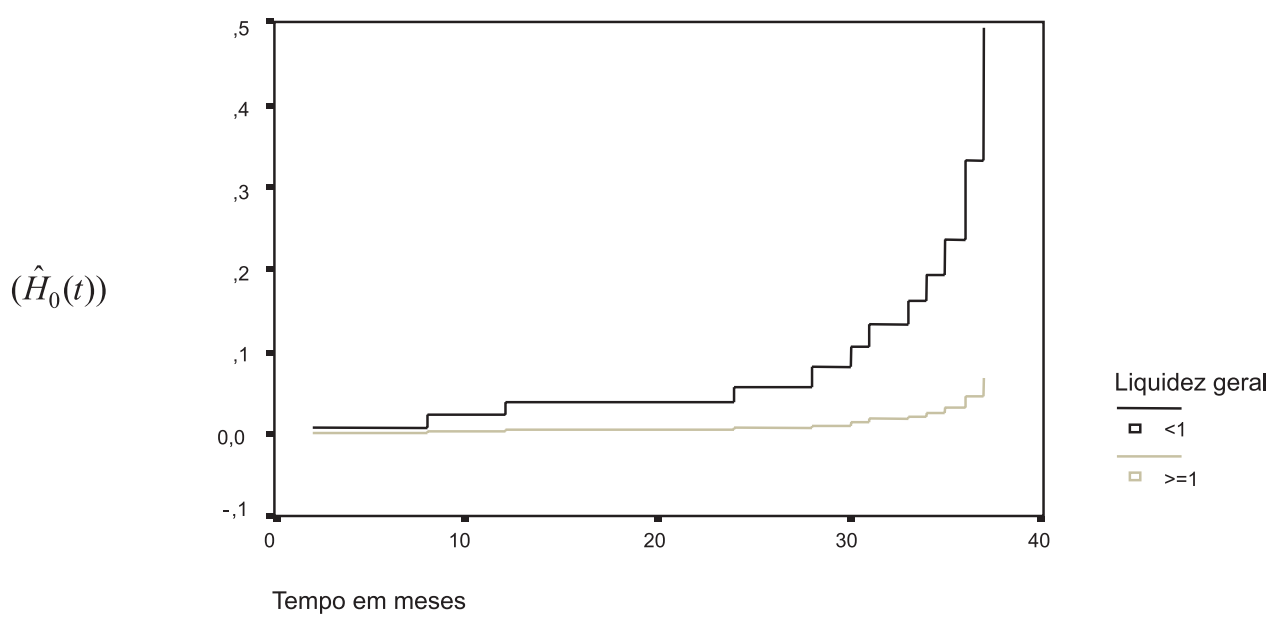


O encaixe, indicador de solvência, também apresentou risco coerente ao esperado, pois, quanto maiores as disponibilidades em relação aos depósitos à vista, menores as probabilidades de ocorrer insolvência nas cooperativas de crédito rural (Gráfico 2). Esse índice com valor 1 indica que o volume de ativo de curto prazo é igual ao passivo de curto prazo, ou seja, a cooperativa consegue cumprir suas obrigações de curto prazo, no entanto não possui excedentes em valores ativos de curto prazo.

O risco das cooperativas de crédito rural que possuem encaixe menor que 1 é 8,34 vezes maior que o risco das que dispõem de encaixe maior que 1. Além disso, pode-se afirmar, com 95\% de confiança, que esse risco varia entre 1,73 e 40,14, outro indicador com dispersão de risco muito grande, o que realça a importância de acompanhar bem de perto a evolução desse indicador financeiro das cooperativas (Gráfico 2).

Com base nos dados de agosto de 2001, verificouse que 6 cooperativas, das 107 que compuseram a amostra, apresentaram o indicador de encaixe menor que 1, isto é, menores disponibilidades em relação aos depósitos à vista, uma situação que pode indicar alguma possibilidade de insolvência. Entretanto, ressalta-se que a insolvência não é determinada por apenas um indicador, e sim por um conjunto de indicadores, informação demonstrada na parte final da discussão dos resultados.

De modo geral, os indicadores de despesas devem sempre ser avaliados pelos dirigentes, pois despesas excessivas certamente resultarão em grandes problemas financeiros. O indicador de despesa com pessoal foi estatisticamente significativo para avaliar o risco relativo de insolvência nas cooperativas de crédito rural do Estado de Minas Gerais. O ponto de corte foi de $-0,005$, ou seja, a despesa representava $0,5 \%$ da captação total.

Esse índice apresentou risco relativo de insolvência conforme o esperado (Gráfico 3), pois, quanto maiores as despesas, maiores os riscos de insolvência. Ressalte-se que o sinal negativo vem do fato de esse índice contemplar contas devedoras, sendo importante avaliar o percentual desprezando o sinal negativo. O risco das cooperativas que possuem despesas com pessoal superiores ou iguais a $0,5 \%$ é de aproximadamente 0,2 vez o risco das que possuem essa despesa menor que $0,5 \%$. Afirma-se também, com $95 \%$ de confiança, que o risco varia entre 0,04 e 0,93. De acordo com o indicador de despesa com pessoal em agosto de 2001, pode-se constatar que 10 cooperativas evidenciavam o risco de insolvência.

Já a receita operacional apresentou ponto de corte de 1,5 , o qual foi calculado, estatisticamente, com base no método de máxima verossimilhança. Esse ponto de corte sinalizou que as cooperativas que tivessem esse indicador menor que 1,5 estariam na faixa de insolvência. No entanto, esse índice exibiu risco de insolvência contrário ao esperado, pois, quanto maiores as receitas, menores as possibilidades de insolvência, e não o contrário.

\section{Gráfico 2 - Função de risco relativo de insolvência para a co-variável encaixe.}

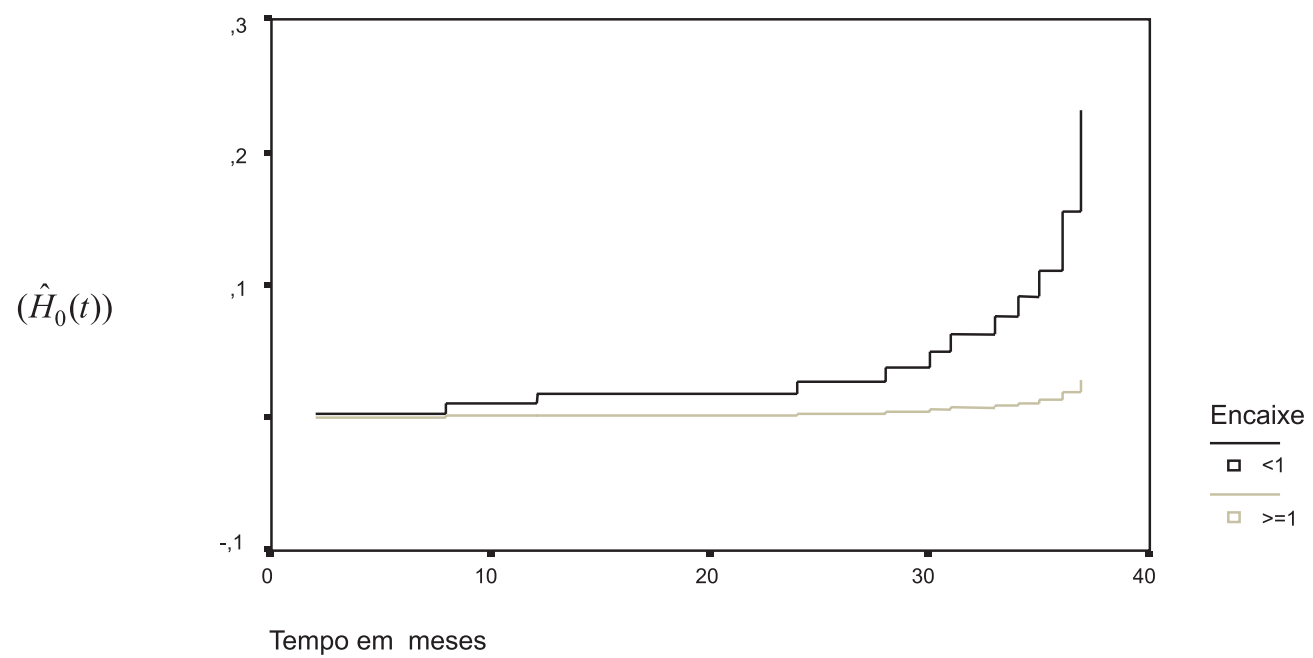


De acordo com a Tabela 2, verificou-se que as cooperativas que apresentaram crescimento da receita operacional menor que 1,5 tinham o risco aproximadamente $40 \%$ maior ao daquelas que possuíam o crescimento da receita operacional superior ou igual a 1,5. Além disso, pode-se afirmar, com 95\% de confiança, que esse risco foi superior a 0,008 .

Ao verificar os motivos pelos quais o indicador de receita operacional apresentou relação de risco contrário ao esperado, constatou-se, por meio da análise dos dados, situação semelhante à do indicador de captação total. Isso porque, das 107 observações, apenas 5 exibiram índice superior ou igual a 1,5; dessas 5 cooperativas, 2 foram classificadas como solventes e 3 como insolventes. Como a maior parte das cooperativas apresentou índice de crescimento da receita operacional menor que 1,5 , o modelo captou que o risco de insolvência seria maior para as instituições com índices maiores que 1,5.

É importante destacar que o aumento da receita operacional implica possível incremento de taxas cobradas aos associados pelas cooperativas, os quais, por sua vez, preferem pagar menores taxas. Entretanto, como a finalidade das cooperativas não é o lucro, e sim o atendimento das necessidades dos associados, o aumento da receita pode indicar exploração do cooperado, no sentido de pagar maiores taxas para, na apuração do resultado final, aumentar as receitas da cooperativa. Nesse sentido, as cooperativas devem buscar o crescimento constante e a melhoria da situação econômico-finan- ceira, avaliando no entanto quais medidas estão sendo utilizadas e se estas promovem vantagens tanto para o cooperado quanto para a instituição.

O índice da alavancagem é formado pela divisão da captação total pelo patrimônio líquido da cooperativa. Assume o ponto de corte de 0,5, ou seja, esse patrimônio representa duas vezes o volume de captação total. Esse índice indica a relação entre o volume de recursos de terceiros em relação aos recursos próprios. Então, quanto maior esse indicador, maior o volume de capital de terceiros e maior o risco; no entanto, se bem administrado, o capital de terceiros pode aumentar a rentabilidade da cooperativa.

A alavancagem também apresentou risco contrário ao esperado, pois, quanto maior a alavancagem (maior a captação de recursos de terceiros), maiores as possibilidades de insolvência. Os resultados evidenciaram que as cooperativas com índices de alavancagem menor que 0,5 têm risco 11 vezes maior de se tornar insolventes, em comparação com as que tiverem esse indicador superior ou igual a 0,5, mas o que se esperava era justamente o contrário: risco maior para cooperativas com maior alavancagem.

A análise dos dados, com o propósito de verificar o porquê do indicador de alavancagem em apresentar risco de insolvência contrário ao esperado, não diferiu muito dos indicadores de crescimento da captação total e do crescimento da receita operacional, os quais também apresentaram risco de insolvência contrário ao esperado. Constatou-se que, de 107 observações,

\section{Gráfico 3 - Função de risco relativo de insolvência para a co-variável despesa com pessoal.}

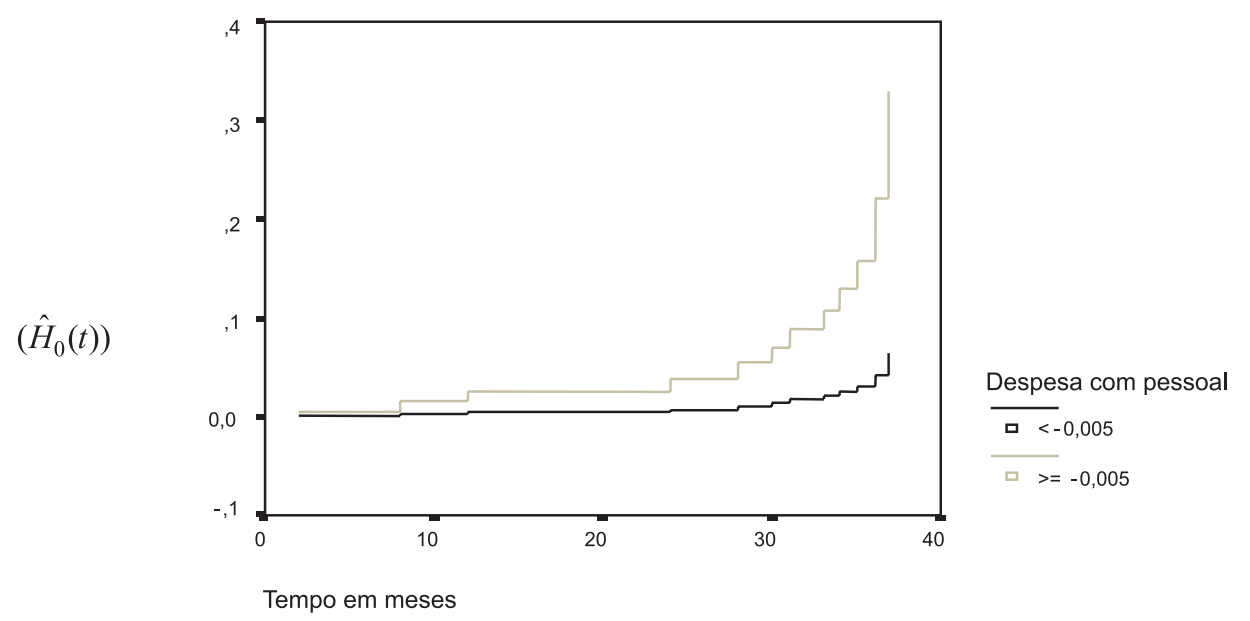


apenas 3 tiveram alavancagem menor que 0,5 e, dessas 3 observações, 2 cooperativas foram classificadas como insolventes e apenas 1 como solvente. Desse modo, o modelo indica que os índices de alavancagem menores que 0,5 aumentariam o risco de insolvência nas cooperativas de crédito rural.

Ainda com base nos resultados, observa-se uma limitação do modelo associada ao critério de dicotomização das variáveis, o qual pode estar contribuindo para esses resultados contraditórios da alavancagem e da captação total. No caso da alavancagem, o ponto de corte pelo método de máxima verossimilhança foi de 0,5 e, analisando a informação das cooperativas, constatou-se que apenas 3 se encontravam com esse indicador menor que 0,5. Dessas 3 cooperativas, 2 foram classificadas como insolventes e 1 como solvente. Já com relação ao indicador de captação total, o ponto de corte foi de 0,8 e, analisando as informações de todas as cooperativas, apenas 5 apresentaram captação menor que 0,8 , e, dessas 5, 2 foram classificadas como solventes e 3 como insolventes. Logo, o critério de definir o ponto de corte pelo método de máxima verossimilhança não foi suficiente para dar suporte à análise de todos os indicadores, pois, como demonstrado, foram poucas as observações com a especificação do ponto de corte, o que comprometeu a análise, apesar de a amostra total das cooperativas de crédito rural ter sido significativa.

De modo geral, o modelo de risco proporcional de Cox sinalizou de modo satisfatório o risco de insolvência nas cooperativas de crédito rural em função de seus indicadores econômico-financeiros. Os indicadores mais relevantes, que apresentaram risco de insolvência compatível com o esperado, foram encaixe, liquidez geral e despesa com pessoal. Constatou-se que apenas 1 cooperativa mostrou, com base nos dados de agosto de 2001, esses indicadores na faixa de risco considerada pelo ponto de corte utilizado no modelo de Cox. Assim, com base nos resultados, é importante que os dirigentes das cooperativas de crédito rural avaliem os indicadores em suas cooperativas, buscando comparar se esses índices encontram-se na faixa dos de cooperativas solventes ou insolventes, de acordo com os pontos de corte estabelecidos neste trabalho.

Os indicadores de encaixe e liquidez geral encontravam-se no grupo de indicadores que forneciam informação sobre a solvência da cooperativa, e, logicamente, a despesa com pessoal indica o grupo de custos e despesas. Nesse aspecto, é importante que os dirigentes procurem maximizar a rentabilidade das cooperativas e minimizar custos. Recomendase que o Conselho Fiscal busque avaliar constantemente as alterações nos balancetes mensais e os motivos dessas alterações no setor de contabilidade da cooperativa, a fim de minimizar eventuais problemas futuros.

\section{CONCLUSÕES}

Com o modelo de risco proporcional de Cox utilizado neste estudo, buscou-se analisar o risco de insolvência das cooperativas de crédito rural em função dos indicadores econômico-financeiros. Os índices identificados como relevantes foram liquidez geral, encaixe e despesa com pessoal. Constatou-se, com base nos indicadores de agosto de 2001, que apenas 1 cooperativa, entre as 107 pesquisadas, encontrava-se na faixa de risco de insolvência determinada pelo modelo. Tal informação permite afirmar que falências, intervenções e fusões de diversas instituições no sistema financeiro brasileiro após o Plano Real não afetaram substancialmente as cooperativas de crédito rural do Estado de Minas Gerais.

Relacionando esses resultados com as características do sistema cooperativo de crédito no Estado de Minas Gerais, pode-se inferir que a centralização financeira das cooperativas de crédito rural no sistema Crediminas traz benefícios em termos da redução do risco de insolvência, uma vez que a instituição é responsável pelo repasse de recursos entre as unidades deficitárias e superavitárias integrantes do sistema.

Em termos da operacionalização do modelo de risco proporcional de Cox, os resultados indicam a importância dos pontos de corte para os indicadores relevantes estimados e a sinalização de risco determinada pelo modelo, fator que permite aos dirigentes avaliar, de acordo com o valor de cada indicador em sua cooperativa, se esta se encontra na faixa de cooperativas solventes ou insolventes e qual seu risco de insolvência.

Vale destacar que a ocorrência de fechamento de cooperativas, que forneceria a informação ex-post para a pesquisa, é muito pequena em comparação com os bancos comerciais. Entretanto, como se trabalhou com 96\% da população das cooperativas do Estado de Minas Gerais, não existiu a possibilidade de aumento do número de cooperativas que encerraram suas atividades.

Outra limitação do presente estudo está associada ao critério ad hoc referente à dicotomização, uma prá- 
tica usada para operacionalizar o modelo, e que, em outras áreas de aplicação, é fundamentado em teorias que determinam os pontos de corte. No caso do presente estudo, os pontos de corte ocorreram em função da amostra. Tal fato não invalida as estimativas, pois o procedimento estatístico para dicotomização apresentou resultados satisfatórios para a maior parte das variáveis significativas do modelo.

Recomendam-se, em trabalhos futuros, estudos que determinem padrões para classificar um banco ou cooperativa como solvente e insolvente, com base em seus indicadores financeiros, de modo a auxiliar a fundamentação teórica para realizar os pontos de corte para o modelo de risco proporcional de Cox, a fim de evitar problemas de estimação de ponto de corte somente com base em métodos estatísticos.

Por fim, vale ressaltar que o presente trabalho objetivou contribuir para a melhor compreensão do cooperativismo de crédito rural em Minas Gerais, além de apresentar a aplicabilidade do modelo de risco proporcional de Cox, o qual permitiu a avaliação do risco relativo de insolvência das cooperativas em função de seus indicadores econômico-financeiros e sua posterior aplicação como ferramenta auxiliar no gerenciamento financeiro das cooperativas de crédito rural.

\section{Artigo recebido em 03.09.2003. Aprovado em 09.01.2004}

\section{Notas}

1. Falha - Consiste na ocorrência do evento; neste caso, insolvência.

2. Censura - Como o modelo de Cox trabalha com duração, é possível que no período de estudo nem todas as cooperativas estejam insolventes ou cheguem a tal situação. Então, essas observações das instituições que não chegaram à insolvência são chamadas de censuras, ou dados censurados.

3. O resultado final é formado da apuração das contas de receita financeira, despesa financeira, receita de serviços, outras despesas operacionais, despesas administrativas, despesas não-operacionais, receitas não-operacionais, provisão para crédito em liquidação e recuperação de crédito em liquidação. Enfim, contempla as principais contas que permitem apurar o resultado da cooperativa. O patamar de $40 \%$ de resultados finais foi estipulado com base nos dados das cooperativas, e constatou-se que apenas $10 \%$ destas possuíam esse percentual de resultados negativos no período, o que permitiu separá-las em dois grupos.

Os autores agradecem as sugestões propostas pelos revisores anônimos, importantes para o aprimoramento do trabalho.

\section{Referências bibliográficas}

ALMEIDA, F. C. L'evaluation des risques de défaillance des enterprises a partir des réseaux de neurones insérés dans les systèmes d'aide à la décision. 1993. 255 p, Thèse (Doctorat en Sciences de Gestion) - Université Pierre Mendès France de Grenoble, Grenoble, 1993.

ALTMAN, E. I. Financial ratios, discriminant analysis and the prediction of corporation bankruptcy. Journal of Finance, v. 23, n. 4, p. 589-609, 1968.

BACKER, M.; GOSMAN, M. L. Financial reporting and business liquidity. New York: National Association of Accountants, 1978.

BENETTI, M. D. Endividamento e crise no cooperativismo empresarial do Rio Grande do Sul: análise do caso Fecotrigo/Centrasul - 1975-83. Porto Alegre: FEE, 1985. p. 253-287.

BERZOINI, R.; SOUZA, P. A. Idéias para um sistema cooperativa de crédito. Gazeta Mercantil, São Paulo,17 abr. 2001. p. A3.

COlOSIMO, E. A. Análise de sobrevivência aplicada. Belo Horizonte: Departamento de Estatística da UFMG, 2001. 151 p. Mimeografado.

COX, C. R. Regression models and life tables. Journal of the Royal Statistical Society, v. 34, n. 2, p. 187-220, 1972.

CREDIMINAS - Cooperativa Central de Crédito Rural de Minas Gerais. Disponível em: <www.crediminas.com.br>. Acesso em: 20 mar. 2001; 29 nov. 2001.

CREDIMINAS EM NOTÍCIA. Chegou o Bancoob, v. 4 (Edição Especial), p. 1-16, set. 1997.

GASQUES, J. G.; VILA VERDE, C. M. Novas fontes de recursos, propostas e experiências de financiamento rural. Revista de Economia e Sociologia Rural, v. 34, n. 3/4, p. 39-80, 1996.

GIMENES, K. M. I. Análise do comportamento dos administradores financeiros com respeito ao custo e estrutura de capital aplicado às cooperativas agropecuárias do Estado do Paraná. 1998. 338 p. Tese (Doutorado) - Universidade de León, Espanha, 1998.

GITMAN, L. J. Princípios de administração financeira. 7. ed. São Paulo: Habra, 1997. 841 p.

JANOT, M. M. Modelos de previsão de insolvência bancária no Brasil: aplicação de diferentes modelos entre 1995 e 1998. 1999. 94 p. Dissertação (Mestrado) - Pontifícia Universidade Católica do Rio de Janeiro, Rio de Janeiro, 1999

KANITZ, S. C. Como prever falências. São Paulo: McGraw-Hill, 1978.

MARTINS, M. S. A previsão de insolvência pelo modelo de Cox: uma contribuição para a análise de companhias abertas brasileiras. 2003. 102 p. Dissertação (Mestrado) - Universidade Federal do Rio Grande do Sul, Porto Alegre, 2003. 
MASY, R. C. Cooperativas de crédito rural e os pequenos produtores no Rio Grande do Sul - Brasil: reorganização e desenvolvimento. Perspectiva Econômica, v. 31, n. 94, p. 5-37, 1996 (Série Cooperativismo, 39).

MATIAS, A. B.; SIQUEIRA, J. O. Risco bancário: modelo de previsão de insolvência de bancos no Brasil. Revista de Administração, v. 31, n. 2, p. 19-28, 1996

MENEGÁRIO, A. H.; ARAÚJo, P. F. C. Emprego de indicadores socioeconômicos na avaliação financeira de cooperativas agropecuárias. Economia Aplicada, v. 5, n. 4, p. 755-788, 2001

MUNOZ, J. Calidad de cartera del sistema bancario y el ciclo económico: una aproximación econométrica para el caso peruano. Disponível em: <www.bcrp.gov.pe/espanol/publicaciones/Revista/Revjul99/tema5.pdf>. Acesso em: 10 maio 2001.

OCB - Organização das Cooperativas Brasileiras. Ramos do cooperativismo. Disponível em: <www.ocb.org>. Acesso em: 06 maio 2001.

OCEMG - Organização das Cooperativas do Estado de Minas Gerais. Banco de dados. Disponível em: <www.ocemg.org.br>. Acesso em: 20 mar. 2001; 06 maio 2001.

PANZUTTI, R. Especificidades da empresa cooperativa agrícola: estratégia de financiamento. Agricultura em São Paulo, v. 44, n. 1, p. 75-118, 1997.
PÉRES, F. Cooperativas criam linhas de produtos para garantir mercados Gazeta Mercantil, São Paulo, 02 mar. 2001. p. 7.

ROCHA, F. Previsão de falência bancária: um modelo de risco proporcional. Pesquisa e Planejamento Econômico, v. 29, n. 1, p. 137-152, 1999.

RODRIGUES, R. L. Cooperativas agropecuárias e relações intersetoriais na economia paranaense: uma análise de insumo-produto. 2000. 171 p. Tese (Doutorado) - Escola Superior de Agricultura Luiz de Queiroz, Piracicaba, 2000

SCHRÖDER, M. O cooperativismo de crédito rural no oeste catarinense: possibilidades e limites de uma alternativa para a agricultura familiar. In: CONGRESSO BRASILEIRO DE ECONOMIA E SOCIOLOGIA RURAL, 37, 1999, Foz do Iguaçu. Anais... Brasília: Sober, 1999.

SESCOOP. Relatório do censo sobre necessidades empresariais das cooperativas de Minas Gerais. Belo Horizonte, Maio 2000. 136 p. Disponível em: <www.ocemg.org.br>. Acesso em: 20 mar. 2001.

SILVA, J. P. Administração de crédito e previsão de insolvência. São Paulo: Atlas, 1983.139 p.

SILVA, J. P. Análise e decisão de crédito. São Paulo: Atlas, 1988. 297 p.

TZIRULNIK, L. Intervenção e liquidação extrajudicial das instituições financeiras. Revista dos Tribunais, 1997. 429 p.

\title{
Valéria Gama Fully Bressan
}

Professora Substituta do CEPEAD/CAD/UFMG. Mestre em Economia Aplicada pela UFV.

Interesses de pesquisa em finanças e cooperativismo.

E-mail: valeriabressan@yahoo.com.br

Endereço: Rua Curitiba, 832, 10ªndar - Centro, Belo Horizonte - MG, 30170-120.

\author{
Marcelo José Braga \\ Professor Adjunto do Departamento de Economia Rural da UFV. Bolsista do CNPq. Doutor \\ em Economia Rural pela UFV. Interesses de pesquisa em agronegócios e cooperativismo. \\ E-mail: mjbraga@ufv.br \\ Endereço: Av. P. H. Rolfs, s/n, Departamento de Economia Rural, Campus UFV, 36570-000.
}

\section{Aureliano Angel Bressan}

Professor Adjunto do CEPEAD/CAD/UFMG. Doutor em Economia Aplicada pela UFV.

Interesses de pesquisa em finanças e econometria.

E-mail: bressan@face.ufmg.br

Endereço: Rua Curitiba, 832, 10ª andar - Centro, Belo Horizonte - MG, 30170-120. 